\title{
Drexel University, the University of Maryland, and their Libraries' Experiences Collaborating with Various Research Programs
}

\author{
$\underline{\text { Jay Bhatt }^{1}}$, Joanne Ferroni ${ }^{2}$, Bob Kackley $^{3}$, and Dorilona Rose ${ }^{4}$ \\ ${ }^{1}$ Drexel University, W. W. Hagerty Library, bhattjj@drexel.edu \\ ${ }^{2}$ Drexel University, Department of Mechanical Engineering and Mechanics, \\ jferroni@cbis.ece.drexel.edu \\ ${ }^{3}$ University of Maryland, University Libraries, rk99@umail.umd.edu \\ ${ }^{4}$ Drexel University, Department of Materials Science and Engineering, \\ drose@ cbis.ece.drexel.edu,
}

\begin{abstract}
Last year, researchers and librarians at both Drexel University and the University of Maryland initiated similar collaborative projects in their respective institutions to contribute to the development of life-long learning skills among the select participants. One joint finding was the importance of linking advances in knowledge, not just as hypothetical learning that benefits an elite few, but rather for the advancement of our society as a whole.
\end{abstract}

Drexel University has two NSF-supported programs, Research Experience for Teachers (RET) and the Research Experience for Undergraduates Site (REU) DREAM (Drexel Research Experience in Advanced Materials). RET's primary goal is to provide experiential engineering education to K-12 teachers in the Delaware Valley. DREAM hosts undergraduates from around the country to work closely with faculty and graduate students in cutting-edge research areas, such as biomaterials, nanomaterials, and the design and processing of advanced materials. In both these programs, the participants learned different skills. For example, in the RET program, participating teachers developed skills that would help them to find, apply for, and secure funding for their schools to improve their classrooms and laboratories. RET participants also worked with their faculty mentors on research projects in emerging technologies, such as nanotechnology, biotechnology, and information technology. The library staff played a key role in helping participants in both programs develop crucial information seeking skills to obtain, evaluate, and use needed research material through a variety of information sources. 
The RET program helps teachers create opportunities to enhance the delivery of science and math education at their schools by helping their students and colleagues learn about science and technology careers and academic opportunities. It is projected that such awareness will motivate more high school students to pursue careers in science, technology, engineering, and mathematics. Participants from the DREAM project may, with the research skills gained, continue with more sophisticated research in new and emerging technology areas after going back to their respective institutions. The program provides possibilities for further collaboration with Drexel researchers.

With similar goals, the University of Maryland's (UM) NSF-funded Gemstone Program focuses on teams of Undergraduate Honors Students that "conduct significant research exploring the interdependence of science and technology with society." This unique, four year, multidisciplinary research program has received significant assistance since 1996 from many UM Librarians in teaching these students critical information-seeking skills for their topical projects and in their senior theses.

Moreover, three UM faculty members created the ESTEEM (Engineering Science and Technology to Energize and Expand Young Minds) Research Mentoring Program that offers high school seniors a chance to be directly involved in university engineering research. Additionally, there are other programs such as Exploring Engineering, Women in Engineering, Stepping Stones to Your Future, and a Girl Scout Engineering Saturday where Girl Scout troops (ages 7-12) engage in fun, hands-on engineering related activities.

This paper describes how faculty, engineering librarians, and organizers from the two universities work together to enhance the success of programs for a diverse user population. The long-term goal is to have knowledge as we know it used for the overall betterment of society in general. This paper describes how faculty and engineering librarians at both Drexel University and the University of Maryland developed similar collaborative projects in their respective institutions to contribute to the development of life-long learning skills among their diverse user groups.

Keywords: Academic Libraries, Engineering Librarianship, Faculty and Library Collaboration, Information Literacy, Library Instruction, Science and Technology Libraries

\section{Various Research Initiatives}

\section{DREAM: Drexel Research Experience in Advanced Materials}


At Drexel, the Department of Materials Science and Engineering (MSE) was selected by the National Science Foundation to host a Research Experience for Undergraduates site entitled, "DREAM: Drexel Research Experience in Advanced Materials." This program was co-directed by the Department Head and the Associate Department Head and was administered by the Program Coordinator of Research and Publications.

In 2004, DREAM enabled eleven undergraduates from a variety of universities, including Ohio State University, Penn State University, Rennselaer Polytechnic Institute, University of Illinois at Urbana-Champaign, University of Massachusetts at Lowell, the University of Pennsylvania, and West Chester University and three Drexel students to work with Drexel faculty members in nanomaterials, biomaterials, and the design and processing of advanced materials. Each DREAM participant received a $\$ 4,000$ stipend to attend the ten-week residential program, during which they worked in research teams with faculty mentors and graduate students. In addition, DREAM students participated in research seminars, demonstrations of cutting-edge research equipment, and a field trip to the Naval Warfare Center Carderock Division. DREAMers also experienced Philadelphia cultural offerings, including the Mann Center for the Performing Arts, the Philadelphia Museum of Art, and the new Citizens Bank Park—home of the Philadelphia Phillies baseball team.

During the program, held from June 14th-August 20th, participants were asked to keep journals, as well as produce an oral presentation on their research and write a written report as if they were submitting an article to a scientific journal. As part of the training, DREAM participants attended two library research sessions to become familiar with the extensive information resources available and to learn how to use them in their research projects. We will describe the library research and instruction component later in the paper.

The DREAM program received high rating from the DREAM Participants, who commented that the experience provided them not only with new knowledge about different areas of materials science and engineering, but also confidence in doing research, giving presentations, and a sense of personal growth.

\section{Research Experience for Teachers: RETAIN \& RET-NANO}

The College of Engineering is also host to two NSF-sponsored Research Experience for Teachers programs entitled, RETAIN (Research Experience for Teachers in Areas of Innovation and Novel Technologies) and RET-NANO (Research Experiences for Teachers in the Area of Nanotechnology). The overarching goal of both RET programs is to educate educators throughout the region on emerging technologies and give them a greater sense of confidence in the laboratory which they can take back to their classrooms.

$\underline{\text { RETAIN Program }}$ 
RETAIN is a five week program designed to educate middle school and high school mathematics and science teachers from the Delaware Valley in the emerging areas of biotechnology, information technology, and nanotechnology. This program provides experiential engineering education through laboratory discovery to educators throughout the Delaware Valley region.

Each participant was paired with a faculty mentor and the mentor's graduate students who are involved in the area of research of interest to the participants. The participants worked alongside their mentors in the laboratory daily during the five week program. The technological education of the teachers participating in this program involved seminars on bridging technology and education, proposal writing, field trips for understanding the implementation of technology in the workplace, and ethics in engineering and education.

The participants in the program were required to develop lesson plans based on their research experiences and provide methods to disseminate their newfound understanding of emerging technologies to student and colleagues. Highlights of the program include: engagement with leading researchers in engineering, 5 weeks of research experiences in the fields of emerging technologies ( 5 days a week for 6 hours a day), \$5,000 stipend for participation, introduction to award-winning Drexel Engineering Curriculum courses, hands-on experience working in a research laboratory, weekly seminars given by School of Education faculty on ways to bridge the technology that they are learning in the laboratory with their classroom teaching, seminars on emerging technology and professional development, field trips illustrating engineering in action, opportunities to enhance delivery of science education at the teachers' respective schools, and certification of Completion in Engineering Laboratory Discovery. Deliverables for the program included a lesson plan integrating technology, a dissemination plan, a website detailing their experience, a grant proposal sketch, and an academic poster.

\section{RET-NANO Program}

RET-NANO is a 5-week program for high school mathematics and science teachers and community college faculty at Drexel University and the University of Pennsylvania. In the summer of 2004, RET-NANO joined the one-year old RET program, RETAIN, to inform twenty high school math and science teachers and community college faculty about the cutting-edge field of nanotechnology. RET Nano is a partnership between Drexel University and the University of Pennsylvania which builds upon the strength of the Drexel Nanotechnology Institute and the Drexel-UPenn NSF funded IGERT fellowship program and is a 3-year project with a budget of \$450K [1].

RET-NANO participants were paired with faculty mentors from both universities and their graduate students in labs. Teachers worked alongside their mentors on cuttingedge nanotechnology research. Deliverables for the program included lesson plans, dissemination methods, and a website. Teachers attended weekly workshops presented by School of Education faculty on developing lesson plans that incorporated their work 
in the laboratories. Other workshops and seminars included proposal writing, preparing students for science, technology, and mathematics (STEM) careers, and engineering ethics. Participants also attended field trips which illustrated engineering in industry. Each of the RET teachers was required to design an academic poster based on their research experience which was presented on the last day of the program. These posters become useful teaching aids for the teacher's after the completion of the program. The goal of RET-NANO is to equip the teachers to go back and teach their students about nanotechnology and inspire them to consider careers in science and engineering.

More information about all three programs is available at:

Drexel Research Experience for Advanced Materials

http://www.materials.drexel.edu/programs/dream reu/

Drexel/NSF RETAIN Technologies in the Delaware Valley

http://www.coe.drexel.edu/ret/

RET-NANO

http://nano.materials.drexel.edu/ret/

As part of the training, the library provided participants in both programs with research workshops to familiarize them with available information and funding sources. The library research and instruction component will be described later in the paper.

\section{Gemstone: University of Maryland (UM) Honors Research Program}

The Gemstone Program was initiated in 1996 by Dr. William Destler, Provost and Senior Vice President of Academic Affairs and former Dean of the James A. Clark School of Engineering, who was convinced that a four year research program such as Gemstone would "trump the Capstone concept"-the Capstone program being a seniors-only design and research program present at many universities [2]. The best description of this NSF-sponsored program “ . ... is a unique multidisciplinary four-year research program for undergraduate honors students of all majors. Under the guidance of faculty mentors and Gemstone staff, teams of students design, direct, and conduct significant research exploring the interdependence of science and technology and society [2]." 
Gemstone is unique in that 1) the faculty mentors allow their Gemstone team students great latitude in their decision-making processes; 2) though most students are from the sciences/engineering, all other majors are included in participation, enhancing the multi-disciplinary aspect; 3 ) the program is four years-the last three years students are on a single team doing long-term research, culminating in a formal thesis/presentation their senior year; and 4) it is a living-learning community with most of the activities centered around one dorm [2]. Through thorough research it was found that very few universities had this type of program available with all components present.

More information can be found at: http://www.gemstone.umd.edu

\section{ESTEEM (and other U.M. Programs)}

Many universities have summer or year-long programs similar to what the University of Maryland sponsors annually in order to enhance interest in science, technology, engineering, and mathematics (STEM) among K-12 students, especially high school juniors and seniors. These programs are in place to encourage high school students to pursue degrees in and subsequent careers in the STEM fields. Several outreach programs at U.M. that stimulate interest in the STEM fields are Exploring Engineering (Women in Engineering), Stepping Stones to Your Future (Engineering Summer Camp), Up Up and Away Program, Upward Bound Math and Science Regional Center, and the ESTEEM Research Mentoring Program. U.M. Librarians have been asked by U.M. faculty and staff to assist them in the majority of these programs, as well as several others not mentioned. These librarians have given instructional sessions to help students learn about the U.M. libraries and the informational sources that are available and most useful to them.

The ESTEEM Research Mentoring Program was created by members of the U.M. Community in 2001 to offer high school seniors the opportunity to participate in structured learning activities focused on engineering research. Students conduct an independent year-long research project under the direction of an engineering faculty member. (More information about this program can be found at http://www.eng.umd.edu/organizations/cmse/pre-college.shtml.) One of the three cofounders, a professor in the Materials Engineering Department, had asked U.M. librarians for library instruction for a number of his ESTEEM groups. Each group is normally composed of ten high school students. Some sample research projects include bone implants and magnetic nano-particles.

\section{Review of Literature}


Collaborative partnerships among university faculty, research departments, students, and librarians play an important role in helping students learn how to find relevant research information needed for their research projects or class assignments. "Information Literacy" is defined by the American Library Association (ALA) as "knowing how to find, evaluate, and use information effectively [3]." When imparting Information Literacy to participants in the programs described above, both Drexel University and University of Maryland librarians were keen on establishing fruitful faculty-librarian collaborations and information exchanges to enhance the academic experience among participants and to foster life-long learning [4]. The objective of the initiated programs has been to support the Information Literacy Competency Standards for Higher Education Document available from the ALA ACRL Standards and Guidelines [3].

The importance and significant impact of collaborations between librarians and faculty members in academic settings has been claimed by a number of research studies. In this section, we review some such studies, identify several approaches that were used for collaborations to happen, and justify why our partnership with faculty and students is fundamental to the attainment of information skills among the participants.

Research collaboration is described as a relationship building process in which two or more individuals work together and in the process, provide their unique contributions and produce new knowledge [5]. The collaboration among librarians, students, faculty, and institutions can provide effective mechanisms to target specific problems faced by students across university campuses. For example, faculty and students across universities need to find, evaluate, and use information needed for their classes or research projects, but are often not familiar or aware of the large number of information tools now available to do so. Using a collaborative framework, they can share their unique problem solving strategies and in the process, come up with a solution to a problem faced by many faculty and students nationwide.

In today's academic environment one that emphasizes an increased demand for producing more and better research and highly employable graduates with efficient information seeking skills, the need for library-faculty partnerships to make this happen is becoming increasingly crucial [6]. With new forms of information and knowledge retrieval systems emerging during the past several years, librarians have become information experts, and are viewed as teachers who impart information literacy skills to their students [6]. With libraries acting as the main gateway for providing access to these resources, librarians have been continuously tasked with not only organizing the complex web of information, but also are key players in teaching students how to use those sources more efficiently [7].

The need for collaboration between faculty members and librarians to design educational activities that will enhance information literacy skills among students is also the subject of the essay on "Information Literacy in Teacher Education [8]." This essay points out the importance of the proposed program model: 
cooperation and collaboration that teaches universal information literacy skills, including the ability to identify a needed area of research, identify an information need, search for information, evaluate that information, refine the search, use the information ethically, and present it effectively and professionally." [8]

Another example of faculty and librarian partnership is well illustrated by Trussell in Librarians and Engineering Faculty: Partnership Opportunities in Information Literacy and Ethics Instruction [7]. Identifying, developing, and implementing information skills should be presented in a way that skills learned in the process are transferable across a wide variety of students' courses. These skills should be maintained and further enhanced through life-long learning. Such skills cannot be taught in isolation and therefore faculty-librarian collaboration becomes an important concept that needs to be fully explored in the process. With their expertise in the use of print and electronic information tools, librarians can adopt a role of "information consultant," where they collaborate with faculty members in the design of assignments requiring instruction in the use of library resources and the development of handouts and information guidebooks that students may find useful in completing their assignments. In the process, they can help students learn important information skills necessary for successfully completing the required assignments or research projects [9]. The consulting role librarians play can also be extended to students, since it is expected that they will need some additional help in accessing, finding, and researching information necessary to complete their assignments. Librarians' individual or group consultations with students can help them to select and use appropriate information sources from a large number of available sources. Awareness of the available sources of information is the first step to comprehensive research, even before learning to use them effectively to locate relevant information.

The importance of librarians collaborating with faculty members to identify what information skills students need to master their courses is outlined in a recent paper on Strengthening Connections Between Information Literacy, General education, and Assessment Efforts [10]. In this paper, faculty members are perceived as providing supporting roles to librarians in assisting them to include important information literacy goals of how to find, evaluate, and use information effectively.

\section{Library Instruction}

As we have seen from several studies conducted among different libraries, it is important to have collaboration among the faculty, the library, students, and the staff to teach students how to find information efficiently. This section describes how collaboration among them was established, how the library instruction was conducted in DREAM and RET programs, and observations on how students learned to acquire information on their research projects. 


\section{Project DREAM}

The Program Coordinator of Research and Publications in the Department of Materials Science and Engineering contacted the Engineering Librarian to explore any possibilities of providing a library session to the students in the NSF-sponsored Research Experience for Undergraduates site during the summer of 2004. Since the participants in the program hailed from universities nationwide, she also needed to know how the library would be able to help provide the students with access to computers in the library, obtain library cards, and give them access to library facilities and resources. A Professor of English and Philosophy working with the DREAM program recommended that the Program Coordinator collaborate with the engineering librarian who had planned and conducted library instruction for the freshman engineering students in her Humanities curriculum as part of the Drexel Engineering Curriculum (tDEC).

In 1989, Professors Eli Fromm and Robert Quinn won a five-year, \$2 million National Science Foundation grant to "enhance the educational experience of engineering students [11]." The project, referred to as E4 (the Enhanced Educational Experience for Engineering students), was driven by the belief that there was a substantial need to update the engineering curriculum [12].

The Drexel Engineering Curriculum (tDEC) design program for freshmen involves about 600 students in approximately 120 teams working on different design projects. While assisting these team-based projects, it was found that the students enjoyed and benefited from both individual and group consultations with the librarians [13]. The design project requires in-depth research on the topic that the students have chosen for their group project. Students work in groups of four to six, collaborating on various facets of the project topic [13]. Since DREAM participants are required to work with Drexel faculty members in research areas such as nanomaterials, biomaterials, and the design and processing of advanced materials, it was decided that the librarians would use a similar approach used with tDEC freshman engineering students to teach information skills, with an emphasis on individual and group consultations. With only 11 students in the DREAM program, it was also decided to incorporate additional instructional opportunities to accommodate more individualized learning.

With this background in mind, the information skills training workshop took place in the library.

The first part of the workshop focused on searching the online library catalog effectively to locate appropriate books in chosen subject areas, identifying and using the collection of online books available from vendors such as Knovel, CRC press (EngNetBase), and Engineering Village2.. 
To reinforce student attention to the content of this workshop, the engineering librarian used an interactive approach where the students and librarian developed a search query together on a topic of the students' interest. This required conversation among them to identify appropriate search terms to be used in the searching process. To make the workshop environment more informal and help increase student participation, the librarian stressed that one of his major goals, aside from teaching information skills, was to create an open, flexible, and friendly environment between students, faculty, and the library to encourage open communication with each other in an amiable fashion. Students were encouraged to ask questions any time during the workshop.

Understanding concepts related to their projects require students to refer to basic information tools such as encyclopedias, books, and handbooks. Drexel's library has electronic subscriptions to many new handbooks and encyclopedias, which allows students to refer to them online from any where at any time by authenticating themselves. These electronic reference tools are cataloged in the online library catalog through easily accessible links. With interactive dialogue between the students and the engineering librarian, the students' areas of research interest were first outlined. Using them as examples, sample searches were conducted to find articles with background information on those research areas such as "biomaterials" and "carbon nanotubes" in different encyclopedias.

Students were able to access any electronically available articles in encyclopedias since each student had access to a computer in the classroom where the workshop was conducted. In order to promote new print reference books, such as the "Encyclopedia of Nanoscience and Nanotechnology," the librarian brought some sample reference books to the classroom and invited each member of the group to carefully observe subject areas covered by looking at the back of the book index. By looking at the index terms, students would be able to develop further insight into the scope and subject matter of the encyclopedia.

The second part of the workshop focused on developing awareness of online abstracting and indexing tools and their use in locating journal articles and conference papers. The electronic databases such as Ei Compendex, INSPEC, IEEE Xplore, PubMed, ScienceDirect, MDConsult and Journals@OVID, were used to illustrate how scientific research papers can be found using them.

During the course of the workshop, the librarian would pose a question related to the concept taught earlier. Based on the responses received, the librarian was able to assess whether students were able to grasp the concepts taught. At the end of the workshop, the librarian formed two groups of five students each. Each group was asked to provide five new things they learned during the workshop. This kept students actively engaged in the learning process, as sometimes one response led to another from a different student, resulting in a stream of new items learned. 
To reinforce what they learned during the workshop, follow-up group sessions were planned in the library during the term. Students were randomly grouped into three separate groups (two groups of four students and one group of 3 students). Each group was invited to come to the library to consult with the librarian independently. Each member of the group was given a laptop with a wireless internet connection. The engineering librarian accompanied the group to a study room and asked group members to access the library's website. During this process, students began to find, locate, and save or e-mail articles on a variety of topics including nylon properties, metallography, particle simulation, biomaterials, tissue engineering, and polygon collision algorithms. The engineering librarian's presence to provide instant consultations to group members played a significant role in helping students get what they needed.

\section{Research Experience for Teachers: RETAIN \& RET-NANO}

Both RETAIN and RET-NANO participants are required to work with faculty members on various research projects. The Director of Outreach in the Department of Mechanical Engineering and Mechanics contacted the engineering librarian to coordinate library workshops for them. Since the participants were all high school and community college teachers with little or no prior experience in researching scientific literature, library workshops were considered crucial for imparting research and information skills to both RETAIN and RET-NANO participants.

Instructional topics, such as searching for print and electronic information, important library procedures, such as interlibrary loan, document delivery and access to the library subscribed electronic resources remotely, and researching funding opportunities for schools from various web based, print, and electronic databases were decided on through consultation with the Director of Outreach. RETAIN had 18 participants who attended seminars, gained hands-on experience working in research laboratories, and visited engineers in their workplace. The RET-NANO program hosted 20 educators, comprised of high school mathematics and science teachers and community college faculty. Two types of library workshops (a total of four) were planned for both RETAIN and RET-NANO Participants. The first workshop focused on searching the online library catalog effectively to locate appropriate books in chosen subject areas, identifying and using the collection of online books available from databases such as Knovel, ENGnetBASE, and Engineering Village2 (Referex), etc., developing awareness of online abstracting and indexing tools such as Ei Compendex, INSPEC, IEEE, PubMed, Science Citation Index and ScienceDirect, etc., and using these tools to find scientific research papers related to their research topic in collaboration with their faculty mentors. Handouts listing important resources with information tips were also provided.

The second workshop involved looking at a variety of funding resources available for teachers in high school and community colleges. Each workshop lasted two hours and both workshops were conducted in an interactive environment such that each 
participant had access to a computer to carry out hands-on searches on a particular research topic using the library's website.

With the help of the Engineering Resources Technician, the engineering librarian provided ample opportunities for interactive consultations with each participant during the course of the workshops.

Numerous funding opportunities are available for teachers and schools to improve their classrooms and laboratories. Urban schools with a dearth in funding can be easily deprived of these opportunities. As a result, one primary focus of the RET program is to educate the RET Participants in the skills of proposal writing for funding availability. With this as a primary focus, the second workshop provided instructional tips on locating various types of available funding resources. Handouts containing a list of useful websites on funding research for schools and community colleges were also provided.

One of the important electronic resources, Community of Science $(C o S)$, was used to illustrate how it can be used to obtain funding alerts via e-mail. Both the engineering librarian and the engineering resources technician ascertained that each participant was following instructions properly while creating and setting up a profile in $C o S$. Based on research keywords selected in the profile, each participant was able to set up a funding alert in $\operatorname{CoS}$ to receive e-mail alerts containing funding opportunities. Other $\operatorname{CoS}$ tools such as CoS Funding Opportunities and CoS Funded Research were also shown during this workshop.

CoS Funding Opportunities is a comprehensive source of funding information, with more than 23,000 records, representing over 400,000 funding opportunities worth over $\$ 33$ billion. COS Funded Research provides for research and tracking information on funding and award histories at leading research facilities around the world. The database features data from the National Institutes of Health (NIH), National Science Foundation (NSF), United States Department of Agriculture (USDA), Small Business Innovation Research (SBIR), and Medical Research Council (MRC).

In addition, resources such as Corporate Philanthropy Report, Foundation Center Online, Nationwide Grant Opportunities for School Teachers, eGrants from the Pennsylvania Department of education, IBM, and other corporate funding opportunities for science and math teachers were also illustrated during this workshop.

Both types of library workshops were considered useful not only by the program coordinators, but also by the students and teachers.

In addition to the library sessions, individual and group consultations, reference desk assistance, and electronic research assistance were also provided. 


\section{Gemstone Program}

Many U.M. Librarians, who volunteer for this three year stint as Gemstone Librarians, are considered by the Gemstone Community to be "a wonderful resource provided for [their] teams" (see http://www.gemstone.umd.edu/Teams/libdirect.htm) and have made many contributions to the Gemstone Program individually, as well as on a campuswide basis. Dr. Neal Kaske, Manager of EPSL (Engineering and Physical Sciences Library) has been the most active librarian for the Gemstone Program since 1996. Three librarians have created, set up, and taught library bibliographic instruction sessions to the approximately fourteen sections of GEMS 100 that are critical for beginning freshman Gemstoners, when they work on what are called "mock projects" that allow them to understand and subsequently use the informational sources available to them through the UM Libraries. In GEMS 201, the three-year team rosters are finalized so each Gemstone Team can begin work on the long-term three-year project to be worked on until graduation. Each team's Gemstone Librarian not only helps the students with the actual sources they will need, but also suggests ways of narrowing chosen topics to help focus them. For instance, one Gemstone Team during the sophomore year started with the idea of solving the traffic woes of five northeast United States cities in GEMS 201; by their senior year, they had focused on a project related to the use of GPS for U.M. buses. The direction and assistance the team received from the Gemstone librarian was one factor in helping them to narrow their topic and gain a better handle on research skills and resources for a more manageable project.

Since the Gemstone program is four years in duration, bibliographic instruction varies according to the circumstances or times it fits the need. The most critical time for library instruction is during the above-mentioned GEMS 201, when the Gemstone Teams are formed for their three-year tenure together. For example, for the project entitled, "Smart Roads," that started off involving Smart Road vehicle development and transformed into an ingenuous scheme related to visible ground-level lane signal switching at congested highway intersections, the Gemstone Librarian introduced the more crucial databases of Ei Compendex (Engineering Index online), INSPEC (online material related to Electrical but also General Engineering), ASCE Database (American Society of Civil Engineers), and TRIS (Transportation Research Information Services) in Civil Engineering, along with others related to Materials Engineering from CSA (Cambridge Scientific Abstracts). Additionally, the U.S. Patent and Trademark Database (http://www.uspto.gov) was introduced to the students along with Espacenet (European Patent Office --- http://ep.espacenet.com). As a result of the success of the project, the "Smart Roads" team now has a United States provisional patent application on file made possible via the University of Maryland's Office of Technology Commercialization

Each Gemstone Librarian follows up with his or her team's information needs, by attending scheduled Gemstone meetings with the team and corresponding faculty 
mentor, helping with informational requests through interlibrary loans, stressing the importance of proper credit for prior work, or assisting in appropriate database searches. Additionally, librarians contribute their time by attending and observing sophomore and junior Gemstone Poster Sessions and critiquing the students' practice thesis presentations in February of their senior year. The program culminates with the Gemstone formal thesis presentations in April, often including Gemstone Librarians as panel experts and thesis judges to recognize the best presentations. There is also a special Gemstone Cap and Gown May Graduation Ceremony when the librarians sit on stage alongside the faculty mentors. The librarians play a pivotal role in the goals and functionality of the Gemstone program.

\section{ESTEEM Program}

It is important for ESTEEM participants, who are all high school students, not to feel intimidated by a large university library. Librarians begin by familiarizing the participants with basic library procedures, such as checking out library materials or interlibrary loans and how to search the U.M. Libraries Catalogue efficiently. Once students are comfortable with these basic methods, they are taught how to use general databases, such as Lexis-Nexis and ingenta, to aid them in a general search on their topics before delving into more subject specific inquiries. As students gain confidence in their library research skills, more subject specific databases, such as Applied Science and Technology (general searches on science and technology topics) and Ei Compendex, are introduced. Finally, as in the Gemstone program, the USPTO site for patents (http://www.uspto.gov) is shown and explained to help find good representations and drawings that can be used in students' projects (e.g., finding patents and related drawings dealing with designing a roller coaster).

\section{How have the collaborations worked?}

To demonstrate the significance of "collaboration" to libraries, at the 2004 IATUL Conference under the sub-theme of "Regional Library Cooperation," there were three presentations which employed the term "collaboration" in the title itself (see link to 2004 IATUL Conference papers). Drexel University and the University of Maryland have taken this concept of "collaboration" beyond that all important link between librarians and faculty members by collaborating between universities on information literacy methods as well.

Charity Hope, in her 2002 article, "The Sum is Greater Than the Parts: CrossInstitutional Collaboration for Information Literacy in Academic Libraries," mentions that from 1997 to 2002, the initiatives and programs between different academic libraries have grown. She adds that these institutional collaborations are usually built on pre-existing relationships within a university system or consortium for this purpose [14]. Drexel University's own Tracy L. Hull, Head of the Information Services Department of the W. W. Hagerty Library, admits that "while collaborations across 
institutions and work place environments can lead to great benefits for all involved, it can also be quite time consuming and require skills than most academic librarians or school media specialists do not normally have [15]."

Collaboration, along with cooperation and coordination, has been a special effort initiated by Jay Bhatt of Drexel University with Bob Kackley of the University of Maryland at the 2004 ASEE Conference (American Society for Engineering Education) in Salt Lake City, UT and quickly included the Program Coordinator of Research and Publications from the Department of Materials Science and Engineering and the Director of Outreach in the Department of Mechanical Engineering and Mechanics, both from Drexel University. Despite the obvious challenges of not being in the same university system or consortium, and dealing with different university information literacy approaches or cultures, Jay's and Bob's collaboration has worked. Through patience and poise, it is possible to work through the hurdles, bringing great rewards to librarians and faculty at both universities, in addition to others looking to embark on similar types of ventures. Throughout the entire process, collaboration took place in a number of instances including partnering with the faculty and program coordinators to decide upon the content of different workshops; working together with participating students to determine what their information needs were and providing tips to meet those needs; communicating with librarians at both institutions dealing with library instruction, various teaching methods, and future presentations at professional conferences; and sharing information about respective programs at the universities. The collaboration experience was almost similar to what Murray Shephered stated in his paper, 'Library Collaboration: What makes it Work?"

\footnotetext{
"The collaboration is not one organisation; we are collaborating organisations linked together. There are still local identities and local cultures that need to be respected and enhanced. Maintaining a balance between collaboration focus and local focus is a key aspect of developing a culture that will be compatible with those at the partner's institutions.'”[16]
}

The mutual bond that evolved contributed to learning experiences among all the participants involved in this project. Feedback about the workshop from program coordinators suggested that even though workshops provided useful information, participants benefited most from individual and small group consultations that included electronic research assistance. For future projects of this type, plans for capturing participant comments, such as individual testimonials, need to be envisioned in advance. This type of feedback is essential for further improving library workshops to meet with the needs of such programs. In essence, feedback can play a crucial role in the success of any collaborative project.

In that sense, are not all the IATUL member libraries able to provide us with unique opportunities to collaborate on different common issues such as information literacy, library management, collection management in an era of growing electronic resources in science and technology, outreach to academic faculty and students, and many other such similar issues? The potential for even more fruitful partnerships is further 
augmented by inviting faculty members and other academic departments of those IATUL member libraries for collaboration. Sharing those findings at future IATUL and other conferences not only helps other members to learn from their experiences, but also brings library awareness to faculty members and their collaborating departments.

\section{References}

1. Kown, K., and Gogotsi, Y. (2004). The Drexel/UPenn IGERT: creating a new model for graduate

education in nanotechnology. The Journal of Materials Education, 26(1-3), pp.147152.

2. Kackley, R., Kaske, N., and Arnold J. (2004). Librarians' Contributions to an Engineering Honor's Program. Proceedings of the 2004 American Society for Engineering Education Annual Conference and Exposition. Retrieved March 23, 2005 from http://eld.lib.ucdavis.edu/conf/conf04.html

3. Association of College and Research Libraries. (2000). Information Literacy Competency Standards for Higher Education. Retrieved March 12, 2004, from http://www.ala.org/ala/acrl/acrlstandards/informationliteracycompetency.htm

4. Bhatt, J., Fromm, E., \& Manion, M. (2004). Engineering ethics, the Drexel Engineering Curriculum and the library - a collaborative teaching partnership. Proceedings of the 2004 American Society for Engineering Education Annual Conference \& Exposition. Retrieved December 12, 2004 from http://www.asee.org/acPapers/2004-773_Final.pdf

5. Stamatoplos, Anthony and Mackoy, Robert. (2004). Collaboration in Library Research. Indiana Libraries, 23(1), pp.2-5

6. Rader, Hannelore. (1998). Faculty-librarian collaboration in building the curriculum for the millennium - the US experience. $64^{\text {th }}$ IFLA General Conference. Retrieved March 12, 2005 from http://www.ifla.org.sg/IV/ifla64/040-112e.htm

7. Trussell, Alice. (2004). Librarians and Engineering Faculty: Partnership Opportunities in Information Literacy and Ethics Instruction. Proceedings of the 25th Annual Conference of the International Association of Technological University Libraries. Retrieved March 16, 2005 from http://www.iatul.org/conference/proceedings/vol14/fulltexts/Alice\%20Trussell.pdf 
8. Crouse, Warren E., Kasbohm, Kristine. (2004). Information Literacy in Teacher Education: A collaborative model. The Educational Forum, 69(1), pp. 44-52.

9. Donham, Jean and Green, Corey. (July 2004). Developing a culture of collaboration: librarian as consultant. Journal of Academic Librarianship., 30(4), pp. 314-321.

10. Rockman, Ilene. (Fall 2002). Strengthening connections between information literacy, general education, and assessment efforts. Library Trends, 51(2), pp. 185-198.

11. Newdick, R. (Oct.1994). E4: the Drexel curriculum. Engineering Science and Education Journal, 3(5), pp. 223-228.

12. Scoles, K., \& Bilgutay, N. (1999). ECE 21: A new curriculum in Electrical and Computer Engineering. 29th ASEE/IEEE Frontiers in Education Conference. pp. 12b5-10-12b5-14.

13. Bhatt, J., and Baldwin, J. (2003). A Collaborative approach toward fostering information literacy in freshman engineering students at Drexel University. Poster presented at the 2003 American Society for Engineering Education Annual Conference \& Exposition: Session 1541.

14. Hope, Charity B. and Peterson, Christina A. (2002). The sum is greater than the parts: cross-institutional collaboration for information literacy in academic libraries. Journal of Library Administration, 36(1/2), pp. 21-38.

15. Hull, Tracy L. and Taylor, Natalia. (2003). Crossing three bridges: linking librarianship and teaching across the P-16 education continuum. The Reference Librarian, 40(83/84), pp. 83-96.

16. Shepherd, M. (2004). Library Collaboration: what makes it work? Proceedings of the $25^{\text {th }}$ IATUL Annual

Conference, vol.14. Retrieved April 12, 2005 from

http://www.iatul.org/conference/proceedings/vol14/fulltexts/Murray\%20Sheperd.pdf 